\title{
UPAYA MINIMALISASI KECURANGAN YANG TERJADI PADA KABUPATEN TIMOR TENGAH SELATAN
}

\author{
Oli Gretia Nitsae
}

Program Studi Magister Akuntansi, Fakultas Ekonomi dan Bisnis, Universitas Brawijaya, gretianitsae@gmail.com

\section{Nurkholis}

Program Studi Magister Akuntansi, Fakultas Ekonomi dan Bisnis, Universitas Brawijaya, nurkholis@ub.ac.id

\section{Lilik Purwanti}

Program Studi Magister Akuntansi, Fakultas Ekonomi dan Bisnis, Universitas Brawijaya, lilikpurwanti64@gmail.com

\begin{abstract}
Abstrak
Penelitian ini bertujuan untuk menguji secara empiris mengenai pengaruh kesesuaian kompensasi, peran auditor internal, dan budaya etis terhadap kecurangan yang dimoderasi SPI pada Pemerintah Daerah Kabupaten Timor Tengah Selatan. Pengujian dilakukan untuk 201 responden yang mewakili pegawai yang memiliki jabatan di instansi pada Pemerintah Daerah Kabupaten Timor Tengah Selatan dengan menggunakan kuesioner. Analisis data dilakukan dengan menggunakan Structural Equation Modeling (SEM). Hasil penelitian menunjukkan bahwa kesesuaian kompensasi dan budaya etis berpengaruh negatif terhadap kecurangan, serta SPI memoderasi kesesuaian kompensasi terhadap kecurangan. Sedangkan, peran auditor internal tidak berpengaruh terhadap kecurangan, serta SPI tidak memoderasi peran auditor internal dan budaya etis terhadap kecurangan. Penelitian ini mendukung teori fraud triangle dimana tekanan dapat diatasi dengan pemberian kompensasi yang sesuai dan budaya etis berperan mengurangi rasionalisasi serta SPI yang baik juga dapat mengurangi kesempatan melakukan kecurangan.
\end{abstract}

Kata Kunci: Kompensasi, Auditor Internal, Budaya Etis, SPI, Kecurangan

\begin{abstract}
This study aims to empirically examine the influence of the appropriatness of compensation, the role of internal auditors, and ethical culture on fraud moderated by the internal control system in the Regional Government of South Central Timor Regency. The test was conducted for 201 respondents representing employees who have positions in institutions in the Regional Government of South Central Timor Regency using a questionnaire. Data analysis was performed using Structural Equation Modeling (SEM). The results showed that the the appropriatness of compensation and ethical culture had a negative effect on fraud, and the internal control system moderated the appropriatness of compensation for fraud. Meanwhile, the role of the internal auditor has no effect on fraud, and the internal control system does not moderate the role of the internal auditor and ethical culture on fraud. This study supports the theory of fraud triangle where the pressure can be treated with appropriate compensation and ethical culture serves to reduce the rationalization and good internal control system can also reduce the opportunity to commit fraud.
\end{abstract}

Keywords: Compensation, Internal Auditors, Ethical Culture, Internal Control Systems, Fraud

\section{PENDAHULUAN}

Fraud merupakan tindakan tidak etis bahkan dipandang sebagai tindakan yang buruk, karena kecurangan sendiri bisa berdampak negatif seperti berkurangnya aset dan rusaknya reputasi (Karyono, 2013:1). Carolina dan Nazir (2019) menyatakan bahwa kecurangan masih menjadi masalah serius di Indonesia. Kasus kecurangan baik itu kecurangan laporan keuangan, penyimpangan aset dan korupsi yang terjadi di lingkungan pemerintah menjadi fenomena yang tidak dapat dipungkiri. Kecurangan terjadi apabila ada motivasi ataupun keadaan yang mendukung pelaku untuk bertindak curang. Motivasi melakukan suatu kecurangan yaitu tekanan untuk melakukan fraud atau pressure, peluang untuk melakukan fraud atau opportunity, serta dalih yang dibuat untuk membenarkan tindakan fraud atau razionalization, yang biasa disebut juga fraud triangle (Permana et al., 2017; Antarwiyati dan Purnomo, 2017; Soehari et al., 2018; Chandrayatna dan Sari, 2019).

Permana et al. (2017) menjelaskan mengenai tekanan bahwa tekanan keuangan maupun non keuangan serta tekanan pribadi dan organisasi yang dirasakan oleh seseorang akan menjadi motivasi untuk melakukan kecurangan. Pemberian kompensasi yang sesuai dari organisasi kepada pegawai dapat mengurangi tekanan keuangan yang menjadi motivasi untuk melakukan kecurangan. Selain itu, kesempatan yang ada juga memungkinkan terjadinya fraud. Kesempatan timbul terutama karena pengendalian internal yang lemah, manajemen tdak efektif dalam pengawasan, atau otoritas yang disalahgunakan (Wahyuni dan 
Budiwitjaksono, 2017). Masalah ini bisa ditangani dengan monitoring melalui pengendalian internal yang efektif. Sedangkan rasionalisasi merupakan pandangan terhadap tindakan sebagai perilaku yang biaa atau wajar, yang secara moral bisa diterima dalam masyarakat normal (Widyaswari,2017). Kebiasaan atau budaya yang ada dalam suatu organisasi bisa menjadi alasan seseorang untuk bertindak dalam setiap aktivitas yang dilakukan dalam organisasi, termasuk kecurangan.

Penelitian ini dilakukan pada Pemerintah Daerah Kabupaten Timor Tengah Selatan (TTS), Provinsi Nusa Tenggara Timur. Dari hasil pemeriksaan BPK, terdapat beberapa permasalahan yang terjadi yaitu masalah penyajian akun yang tidak tepat dengan SAP yang berlaku dan bukti tidak cukup pada LKPD tahun 2017 untuk akun aset lancar, aset tetap, dan belanja operasi-LO. Kesalahan ini juga terjadi pada LKPD tahun-tahun sebelumnya. Selain itu, pada tahun 2015 dan tahun 2016 ada permasalahan dalam pengelolaan dan pertanggungjawaban dana dan kegiatan serta penyediaan sarana prasarana yang terkait dengan pendidikan, penanggulangan kemiskinan dan air minum (IHPS BPK, 2015-2018).

Pemerintah daerah Kabupaten TTS juga menghadapi kasus penyimpangan anggaran pada tahun 2002 sampai tahun 2016. Terdapat manipulasi pertanggungjawaban administrasi atas dana sebesar Rp.25 miliar lebih yang merugikan daerah. Ini merupakan temuan BPK dan Inspektorat yang ada di propinsi dan kabupaten TTS. Kebocoran dana yang dituntut pengembaliannya pada tahun 2017 ini terdiri dari 174 kasus dengan jumlah dana yang bervariasi untuk setiap kasus yang terjadi di OPD, kecamatan hingga desa (Diakses dari: http://fakta-tts.com/). Selain itu, masih terdapat berbagai kasus kecurangan yang terjadi di Kabupaten Timor Tengah Selatan. Permasalahan-permasalahan inilah yang menjadi motivasi peneliti untuk melakukan penelitian terkait dengan kecurangan pengelolaan keuangan di lingkungan pemerintahan, khususnya Kabupaten TTS.

\section{TINJAUAN TEORITIS DAN PENGEMBANGAN HIPOTESIS}

Teori fraud triangle adalah salah satu teori yang menjelaskan mengenai kecurangan. Teori ini merupakan teori yang dikembangkan oleh kriminolog Donald Ray Cressey pada tahun 1953 melalui penelitian yang dilakukannya. Teori ini menyimpulkan tiga motivasi seseorang melakukan kecurangan. Pertama, pelaku fraud memiliki kebutuhan mendesak yang dirahasiakan karena keadaan (pressure). Kedua,pelaku fraud yang memiliki kesempatan untuk melakukan penipuan (opportunity). Ketiga, rationalization dimana pelaku fraud mencari pembenaran untuk perbuatan curang sejalan dengan norma yang diterima pribadi mereka (Priantara, 2013:44).

Teori ini telah digunakan oleh banyak peneliti dalam melakukan penelitian terkait kecurangan. Fitri dan Nadirsyah (2019) menjelaskan bahwa tekanan yang menjadi motivasi melakukan kecurangan meliputi tekanan finansial maupun tekanan non-finansial seperti tekanan pekerjaan dan tekanan lain. Muhammad dan Ridwan (2017) serta Aswad et al (2018) menemukan bahwa adanya kompensasi yang sesuai bisa menekan terjadinya fraud. Hal ini dikarenakan kesesuaian kompensasi yang diterima pegawai akan menjadi pemicu untuk melakukan pekerjaan baik dan tidak melakukan tindakan merugikan seperti fraud.

Antarwiyati dan Purnomo (2017) yang juga menggunakan teori yang sama menjelaskan peningkatan peluang untuk berbuat curang disebabkan oleh kelemahan sistem pengendalian internal, kurang akses terhadap informasi, kurangnya upaya melakukan jejak audit dan lainnya. Upaya untuk meminimalkan peluang terjadinya kecurangan adalah dengan meningkatkan keefektifan pelaksanaan SPI serta peningkatan peran dari auditor internal (Zelmiyanti dan Anita, 2015). Pua et al (2017) menyatakan bahwa auditor internal yang melakukan perannya sesuai dengan standar dapat mendeteksi kecurangan dan juga mencegah kecurangan yang akan terjadi.

Rasionalisasi yang dijelaskan oleh Putra dan Latrini (2018) sebagai bagian yang sulit untuk diukur dari teori fraud triangle, karena berkaitan dengan usaha pelaku kecurangan yang berusaha untuk mencari pembenaran yang rasional untuk membuktikan bahwa kecurangan yang dilakukan adalah tindakan yang benar. Budaya atau kebiasaan yang terjadi dalam suatu organisasi dapat menjadi alasan seseorang dalam bertindak sehingga diperlukan penerapan budaya yang etis dalam organisasi. Chandrayatna dan Sari (2019), Putra dan Latrini (2018) serta Zelmiyanti dan Anita (2015) juga membuktikan bahwa budaya etis memiliki pengaruh menurunkan fraud.

Sistem pengendalian internal berperan sebagai variabel moderasi karena terdapat inkonsistensi hasil penelitian antara variabel kesesuaian kompensasi, peran auditor internal, dan budaya etis dengan kecurangan. Selain itu, SPI juga mampu menghubungkan variabel yang lain dengan kecurangan dalam penelitian Zelmiyanti dan Anita 
(2015) dan Lorensa et al (2018). Sistem pengendalian internal juga merupakan sistem yang diciptakan untuk mengontrol kegiatan organisasi sehingga tidak terjadi kecurangan.

\section{Kesesuaian Kompensasi dan Kecurangan}

Kesesuaian kompensasi merupakan alternatif untuk mengatasi tekanan yang dirasakan seseorang yang bisa menjadi motivasi dalam melakukan kecurangan. Muhammad dan Ridwan (2017) serta Aswad et al (2018) menemukan bahwa kesesuaian kompensasi bisa menekan terjadinya fraud. Hal ini dikarenakan kompensasi tersebut bisa mendorong karyawan untuk melakukan pekerjaan yang baik, sehingga tindakan merugikan seperti fraud tidak akan dilakukan. Kesesuaian Kompensasi merupakan timbal balik dari instansi yang adil kepada seseorang akibat pekerjaan yang sudah dilakukan (Dewi et al., 2017). Dewi et al. (2017), Ramadhany et al. (2017), Muhammad dan Ridwan (2017), serta Aswad et al. (2018), Soehari et al. (2018) menemukan bahwa kesesuaian kompensasi mempunyai pengaruh negatif atas fraud di sektor pemerintahan yang berarti bahwa semakin sesuai pemberian kompensasi kepada pegawai maka akan mengurangi tindakan fraud di lingkungan pemerintah. Hal ini menjadi dasar dugaan bahwa tingginya kesesuaian kompensasi dapat menekan kecurangan.

H1: Kesesuaian kompensasi berpengaruh negatif terhadap kecurangan

\section{Peran Auditor Internal dan Kecurangan}

Kesempatan melakukan kecuranggan timbul terutama karena pengendalian internal yang lemah, manajemen tidak efektif dalam pengawasan, atau otoritas yang disalahgunakan (Wahyuni dan Budiwitjaksono, 2017). Fungsi auditor internal adalah melakukan pengawasan terhadap SPI dan mengevaluasi manajemen dan memberi anjuran jika ada kelemahan penerapan sistem dan penyimpangan (Darmawiguna dan Mimba, 2017; Lorensa, et al., 2018). Zelmiyanti dan Anita (2015) juga berpendapat bahwa upaya untuk meminimalkan peluang terjadinya kecurangan adalah dengan meningkatkan keefektifan penerapan SPI dan peningkatan peran auditor internal. Pua et al. (2017) menyatakan bahwa auditor internal yang melakukan perannya sesuai dengan standar dapat mendeteksi kecurangan dan juga mencegah kecurangan yang akan terjadi. sedangkan, penelitian yang dilakukan Fitri (2018) juga menemukan bahwa peran auditor mempunyai pengaruh untuk mencegah kecurangan sehingga auditor internal sangat dibutuhkan didalam organisasi untuk melakukan pengendalian dan mengevaluasi aktivitas dan kegiatan organisasi terutama dalam pencegahan fraud. Hal ini menjadi dasar dugaan bahwa tingginya peran auditor internal akan menekan terjadinya fraud.

H2: Peran auditor internal berpengaruh negatif terhadap kecurangan

\section{Budaya Etis dan Kecurangan}

Budaya atau kebiasaan yang terjadi dalam suatu organisasi dapat menjadi alasan seseorang dalam bertindak sehingga diperlukan penerapan budaya yang etis dalam organisasi. Rasionalisasi adalah wujud pembenaran atas tindakan curang sehingga tidak ada rasa salah dan penyesalan atas tindakan tersebut, jika rasionalisasi semakin tinggi maka akan meningkatkan percaya diri seseorang untuk bertindak curang tanpa penyesalan (Fitri dan Nadirsyah, 2019). Budaya yang tidak baik atau tidak etis yang sudah terbentuk kuat dalam suatu organisasi bisa menjadi alasan seseorang untuk membenaran tindakan kecurangan. Penelitian Virmayani (2017), Rosliana (2018), Putra dan Latrini (2018), Chandrayatna dan Sari (2019) menunjukan bahwa budaya etis mempunyai pengaruh negatif terhadap fraud yang berarti bahwa budaya yang etis dapat menekan terjadinya kecurangan. Hal ini menjadi dasar dugaan bahwa tingginya budaya etis organisasi dapat menekan terjadinya fraud.

H3: Budaya etis berpengaruh negatif terhadap kecurangan

\section{Pengaruh Moderasi dari Sistem Pengendalian Internal}

Menurut Putra dan Latrini (2018), pengendalian internal dinyatakan baik jika bisa meminimalisasi tindak kecurangan. Hal ini dikarenakan SPI adalah sistem yang dirancang untuk menekan dan meminimalisir terjadinya kecurangan. Pengertian SPI menurut PP No.60/2008 adalah keterpaduan proses yang dilakukan secara terus menerus terhadap kegiatan oleh semua pihak dalam organisasi untuk mencapai suatu keyakinan yang memadai atas pencapaian tujuan lewat keefektifan dan efisiensi kegiatan, pelaporan keuangan yang andal, pengamanan atas aset negara, dan kepatuhan terhadap peraturan. Jaminan dari SPI ini yang kemudian menjadi kekuatan organisasi dalam mengendalikan kecurangan.

Struktur pengendalian intern yang memenuhi syarat dirancang oleh manajemen untuk bisa mencapai tujuan. Rancangan ini dapat mengotomatiskan pengendalian serta pengawasan 
kepada pekerjaan dalam organisasi dan bisa mengurangi kecurangan (Ramadhany et al, 2017). Peluang yang mengakibatkan terjadinya kecurangan bisa dicegah melalui penerapan SPI yang baik (Putra dan Latrini, 2018). Permana et al (2017) juga menemukan bahwa sistem pengendalian yang berjalan secara efektif dapat mengurangi potensi terjadinya kecurangan di lembaga pemerintahan. Penelitian-penelitian empiris juga mendukung peran SPI dalam mengurangi kecurangan. Penelitian yang dilakukan oleh Alou et al. (2017), Dewi et al. (2017), Ramadhany et al. (2017), Muhammad dan Ridwan (2017), Putra dan Latrini (2018), Chandrayatna dan sari (2019) menemukan bahwa pelaksanaan SPI yang sesuai dan efektif dapat meminimalkan terjadinya kecurangan dalam organisasi. Selain itu, sistem pengendalian internal juga terbukti mampu menjadi penghubung variabel-variabel lain dengan kecurangan dalam penelitian Zelmiyanti dan Anita (2015) dan Lorensa et al. (2018). Hal ini membuktikan bahwa SPI dapat memperkuat hubungan antara variabel-variabel penelitian dan kecurangan.

Kompensasi merupakan hal penting dalam suatu organisasi karena merupakan bentuk timbal balik dari organisasi terhadap pegawai. Menurut Ramadhany et al (2017), keinginan untuk memaksimalkan pendapatan adalah penyebab dari kecurangan yang dilakukan oleh pegawai. Ketika kompensasi diberikan sesuai maka pegawai tidak akan melakukan kecurangan. Aswad et al (2018) berpendapat bahwa kepatuhan individu terhadap ketetapan organisasi dipengaruhi oleh kompensasi yang adil dan sesuai serta keefektifan SPI. Hal ini menjelaskan bahwa kompensasi dan sistem pengendalian intern dapat mengurangi fraud. Penjelasan di atas menjadi dasar perumusan hipotesis berikut:

H4: Sistem pengendalian internal memperkuat pengaruh kesesuaian kompensasi terhadap kecurangan

Auditor internal mempunyai tanggung jawab melakukan pemeriksaan dan evaluasi efektivitas SPI dalam rangka mencegah kecurangan (Lorensa et al, 2018). Pua et al (2017) berpendapat bahwa penetapan kriteria yang cukup dan memadai oleh manajemen yang digunakan dalam organisasi untuk melihat tercapai atau tidaknya tujuan harus dipastikan oleh auditor internal. Hal ini menunjukan penerapan dari SPI perlu dilakukan secara efektif sehingga dapat mendukung peran dari auditor internal dalam mengurangi resiko terjadinya fraud. Penjelasan di atas menjadi dasar perumusan hipotesis berikut:
H5: Sistem pengendalian internal memperkuat pengaruh Peran auditor internal terhadap kecurangan

Fraud dapat dihindari melalui penerapan budaya yang etis karena tindakan beretika hanya terjadi dalam lingkungan yang etis (Rosliana, 2018). Lorensa et al (2018) menyatakan bahwa budaya dari organisasi berperan sebagai alat pertimbangan dan cara yang menjadi acuan setiap individu dalam bersikap di organisasi. Artinya bahwa keefektifan suatu organisasi dapat ditingkatkan dan bisa mengurangi fraud melalui penerapan budaya khususnya pada pengendalian internal. Penjelasan di atas menjadi dasar perumusan hipotesis berikut:

H6: Sistem pengendalian internal memperkuat pengaruh budaya etis organisasi terhadap kecurangan

\section{METODE PENELITIAN}

Penelitian ini merupakan penelitian dengan pendekatan kuatitatif dan jenis penelitian penjelasan yaitu penelitian yang menguraikan hubungan antar variabel penelitian melalui pengujian hipotesis. Penelitian ini dilakukan pada Pemerintah Daerah Kabupaten Timor Tengah Selatan. Populasinya adalah ASN yang ada di lingkungan pemerintah daerah Kabupaten Timor Tengah Selatan yang bersedia mengisi kuesioner yang tersebar di 76 organisasi perangkat daerah. Teknik pengambilan sampel menggunakan convenience sampling, teknik ini digunakan karena mempertimbangkan kesediaan responden dalam memberikan informasi dan data yang berkaitan dengan penelitian (Sekaran, 2016:136). Jumlah sampel yang akan diuji dalam penelitian ini adalah sebanyak 201 orang. Data yang diperoleh dari kuesioner dianalisis menggunakan SEM-PLS (SEM-Partial Least Square).

Variabel penelitian ini adalah kecurangan, kesesuaian kompensasi, budaya etis, peran auditor internal, dan sistem pengendalian internal. Indikator dari variabel ini dikembangkan dalam item pertanyaan menjadi instrumen penelitian atau kuesioner yang disebarkan kepada responden. Definisi operasional dari setiap variabel dijelaskan dalam tabel berikut:

Tabel 1. Definisi Operasional Variabel

\begin{tabular}{lc}
\hline \multicolumn{1}{c}{ Variabel } & $\begin{array}{c}\text { Indikator Pengukuran } \\
\text { dan Sumber }\end{array}$ \\
\hline $\begin{array}{l}\text { Kecurangan (Y) adalah tindakan } \\
\text { penipuan yang dirancang dan }\end{array}$ & $\bullet$ Kecurangan laporan \\
sengaja dilakukan oleh seseorang & $\bullet$ Peuangan \\
dan/atau kelompok untuk & $\bullet$ Korupsi \\
memperoleh keuntungan pribadi. & Fitri dan Nadirsyah \\
\hline
\end{tabular}


Oli Gretia Nitsae : Upaya Minimalisasi Kecurangan Yang Terjadi.....

(2019)

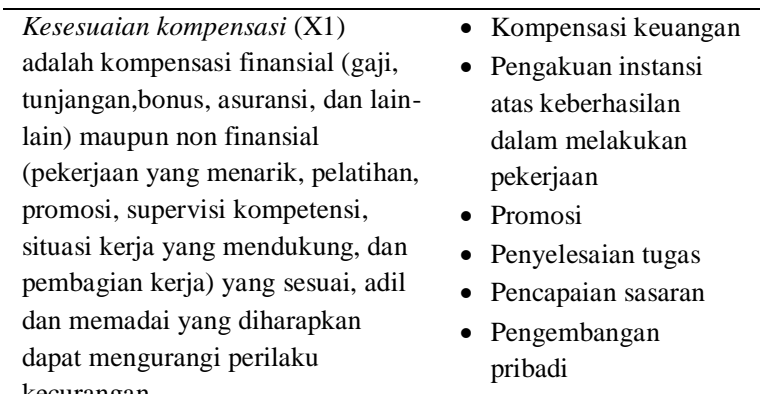

Kurniasari (2017) dan

Aswad et al (2018)

Peran auditor internal (X2) adalah $\quad$ - Assurance activities

sebagai pihak yang melakukan - Anti-corruption

berbagai aktifitas dengan tujuan

mendeteksi, mencegah, dan

meninvestigasi kecurangan.

- Consulting activities

Standar Audit Intern

Pemerintah Indonesia (2015)

Budaya etis (X3) adalah panutan

bagi semua pihak dalam bentuk

norma, nilai, perilaku dan tindakan

yang diterima secara hukum dan

moral dalam berperilaku dan

berinteraksi di organisasi.

Model peran yang visible

- Komunikasi harapanharapan etis

- Pelatihan etika

- Hukuman bagi tindakan etis

- Mekanisme perlindungan etika

Chandrayatna dan Sari (2019) dan Kurniasari (2017)

Sistem pengendalian internal $(\mathrm{Z}) \quad \bullet$ Lingkungan

adalah keterpaduan proses yang pengendalian

dilakukan secara terus menerus - Penilaian resiko

terhadap kegiatan oleh semua pihak - Kegiatan

dalam organisasi untuk mencapai

suatu keyakinan yang memadai atas

pencapaian tujuan lewat

pengendalian

- Informasi dan

komunikasi

keefektifan dan efisiensi kegiatan,

pelaporan keuangan yang andal,

pengamanan atas aset negara, dan

kepatuhan terhadap peraturan.

- Pemantauan

PP No.60 tahun 2008 dan Chandrayatna dan Sari (2019)

\section{HASIL DAN PEMBAHASAN}

Data yang didapat melalui penyebaran kuesioner penelitian kepada responden terdiri dari 300 kuesioner yang disebarkan di Pemkab TTS, sebanyak 212 kuesioner penelitian telah diterima kembali oleh peneliti. Dari jumlah tersebut hanya terdapat 201 kuesioner yang dapat diolah. Pengolahan data menggunakan aplikasi WarpPLS 6.0 .

Pada tahap awal pengujian PLS (Part Least Square), dilakukan dengan melakukan evaluasi outer model dan inner model. Pengujian outer model melalui uji validitas dan diskriminan dari parameter AVE, communality, outer loading, cronbach's alpha, dan composite reliability.
Sedangkan pengujian inner model dengan melihat nilai signifikansi.

Tabel 2. Hasil Pengujian Validitas dan Reliabilitas

\begin{tabular}{|c|c|c|c|c|c|}
\hline Ind. & Loading & $\begin{array}{c}\mathrm{P} \\
\text { Value }\end{array}$ & AVE & $\begin{array}{l}\text { Composite } \\
\text { Reliability }\end{array}$ & $\begin{array}{c}\text { Cronbach's } \\
\text { Alpha }\end{array}$ \\
\hline $\mathrm{X} 1.1$ & 0,719 & $<0,001$ & & & \\
\hline $\mathrm{X} 1.2$ & 0,800 & $<0,001$ & & & \\
\hline $\mathrm{X} 1.3$ & 0,772 & $<0,001$ & 0,609 & 0,886 & 0,838 \\
\hline X1.4 & 0,867 & $<0,001$ & & & \\
\hline X1.6 & 0,735 & $<0,001$ & & & \\
\hline $\mathrm{X} 2.1$ & 0,863 & $<0,001$ & & & \\
\hline $\mathrm{X} 2.2$ & 0,885 & $<0,001$ & 0,770 & 0,909 & 0,850 \\
\hline $\mathrm{X} 2.3$ & 0,884 & $<0,001$ & & & \\
\hline X3.1 & 0,761 & $<0,001$ & & & \\
\hline X3.2 & 0,789 & $<0,001$ & & & \\
\hline X3.3 & 0,804 & $<0,001$ & 0,632 & 0,896 & 0,854 \\
\hline X3.4 & 0,807 & $<0,001$ & & & \\
\hline X3.5 & 0,812 & $<0,001$ & & & \\
\hline Z.1 & 0,796 & $<0,001$ & & & \\
\hline $\mathrm{Z} .2$ & 0,829 & $<0,001$ & & & \\
\hline Z.3 & 0,819 & $<0,001$ & 0,645 & 0.901 & 0,862 \\
\hline $\mathrm{Z} .4$ & 0,777 & $<0,001$ & & & \\
\hline Z.5 & 0,794 & $<0,001$ & & & \\
\hline Y.1 & 0,863 & $<0,001$ & & & \\
\hline Y.2 & 0,923 & $<0,001$ & 0,777 & 0,913 & 0,856 \\
\hline Y.3 & 0,857 & $<0,001$ & & & \\
\hline
\end{tabular}

Sumber: Hasil pengolahan data primer

Instrumen penelitian juga diuji validitas dan realibilitasnya. Hasil pengujian dinyatakan dalam tabel 2 di atas. Validitas data dilihat dari nilai loading setiap indikator ( $>0.7$ ) dan nilai $A V E$ (>0.5), sedangkan realibilitas dilihat dari nillai cronbach's alpha dan composite reliability yang lebih dari 0.7. Pengujian yang dilakukan menunjukan bahwa data yang diolah valid dan reliabel sehingga dilakukan pengujian selanjutnya untuk menguji hipotesis penelitian.

Signifikansi koefisien jalur dari partial least square (PLS) dilakukan dalam pengujian hipotesis, besarnya pengaruh ditunjukan dalam koefisien jalur. Pernyataan variabel eksogen berpengaruh secara signifikan terhadap variabel endogen dinyatakan apabila nilai koefisien jalur signifikan. Pengujian pengaruh langsung dan pengaruh moderasi juga menggunakan Nilai koefisien jalur yang diperoleh dari Partial Least Square (PLS).

Tabel 3. Hasil Pengujian Hipotesis

\begin{tabular}{ccccc}
\hline Hipotesis & $\begin{array}{c}\text { Koefisien } \\
\text { Jalur }\end{array}$ & $\begin{array}{c}\text { Standard } \\
\text { Erorrs }\end{array}$ & $\begin{array}{c}\text { P- } \\
\text { value }\end{array}$ & Ket. \\
\hline H1 & $-0,151$ & 0,069 & 0,014 & $\begin{array}{c}\text { Hipotesis } \\
\text { Diterima }\end{array}$
\end{tabular}


Journal of Public Sector Innovations, Vol. 4, No. 2, Mei Tahun 2020, (75-83)

\begin{tabular}{|c|c|c|c|c|}
\hline Hipotesis & $\begin{array}{c}\text { Koefisien } \\
\text { Jalur }\end{array}$ & $\begin{array}{c}\text { Standard } \\
\text { Erorrs }\end{array}$ & $\begin{array}{c}\mathrm{P}- \\
\text { value }\end{array}$ & Ket. \\
\hline $\mathrm{H} 2$ & $-0,054$ & 0,070 & 0,219 & $\begin{array}{c}\text { Hipotesis } \\
\text { Ditolak }\end{array}$ \\
\hline $\mathrm{H} 3$ & $-0,341$ & 0,066 & $<0,001$ & $\begin{array}{l}\text { Hipotesis } \\
\text { Diterima }\end{array}$ \\
\hline $\mathrm{H} 4$ & 0,133 & 0,069 & 0,028 & $\begin{array}{c}\text { Hipotesis } \\
\text { Diterima }\end{array}$ \\
\hline H5 & $-0,041$ & 0,070 & 0,278 & $\begin{array}{c}\text { Hipotesis } \\
\text { Ditolak }\end{array}$ \\
\hline H6 & $-0,073$ & 0,070 & 0,148 & $\begin{array}{c}\text { Hipotesis } \\
\text { Ditolak }\end{array}$ \\
\hline
\end{tabular}

Hasil pengujian $\mathrm{H} 1$ menunjukkan ada pengaruh negatif antara kesesuaian kompensasi dan kecurangan. Ketika kompensasi yang diterima oleh pegawai sesuai dan adil maka dapat mengurangi tidakan dan perilaku kecurangan dari pegawai. Hasil ini mendukung penelitian Dewi et al (2017), Ramadhany et al (2017), Muhammad dan Ridwan (2017), Soehari et al (2018) serta Aswad et al (2018). Hasil penelitian juga mendukung teori fraud triangle. Salah satu motivasi kecurangan adalah karena adanya tekanan dari berbagai hal seperti tekanan keuangan, pekerjaan dan keluarga. Kompensasi yang diberikan menjadi solusi untuk mengurangi tekanan, baik tekanan keuangan maupun tekanan pekerjaan. Penilaian akan kesesuaian kompensasi memang cukup kompleks karena kebutuhan pegawai yang beragam namun kesesuaian antara beban kerja dan kompensasi yang diberikan bisa dinilai sebagai kompensasi yang adil dan sesuai. Artinya kompensasi yang diberikan tidak berlebihan yang berakibat pada kecemburuan pegawai lain dan juga tidak kekurangan yang berakibat pada tidak terpenuhi kebutuhan pegawai.

Hasil pengujian $\mathrm{H} 2$ menunjukkan tidak ada pengaruh negatif antara peran auditor internal dan kecurangan. Hasil ini tidak dapat membuktikan bahwa auditor internal mampu meminimalkan kesempatan terjadinya kecurangan. Sebagai aktor yang berperan dalam mencegah kecurangan, auditor internal di lingkungan pemerintah kabupaten TTS belum mampu mengurangi kecurangan yang ada di lingkungan pemerintah daerah kabupaten TTS. Lorensa et al (2018) menyatakan beberapa kemungkinan auditor internal belum mampu mengurangi kecurangan adalah bahwa peran dan kemampuan profesional dari auditor internal belum maksimal dilakukan dalam proses pemeriksaan untuk dapat mencegah kecurangan. Peran dan tanggung jawab auditor internal mencakup assurance activities, anticorruption activities dan consulting activities (Asosiasi Auditor Intern Pemerintah Indonesia, 2014). Hal lain yang menjadi alasan auditor internal tidak dapat mengurangi kecurangan adalah bahwa auditor internal bisa melakukan peran sebagai auditor dan pengawas sistem yang berjalan dalam suatu organisasi, namun auditor internal sebagai individu belum mampu atau bahkan tidak mampu untuk mengendalikan perilaku seseorang termasuk pelaku kecurangan.

Hasil pengujian $\mathrm{H} 3$ menunjukkan ada pengaruh negatif antara budaya etis dan kecurangan. Ketika budaya yang ada adalah budaya yang etis maka kecenderungan berbuat curang akan berkurang. Hasil ini mendukung penelitian Virmayani (2017), Rosliana (2018), Putra dan Latrini (2018), Chandrayatna dan Sari (2019). Hasil penelitian juga mendukung teori fraud triangle. Salah satu motivasi tindak kecurangan adalah terdapat alasan untuk merasionalisasikan kecurangan yang dilakukan. Cara menghindari rasionalisasi adalah dengan mencegah adanya keadaan yang bisa menjadi alasan melakukan kecurangan melalui peningkatan budaya yang etis dalam organisasi. Perilaku curang akan dianggap sebagai perbuatan melanggar etika dalam suatu budaya etis sehingga individu dalam organisasi akan cenderung menghindari perilaku curang.

Hasil pengujian H4 menunjukkan bahwa SPI memperkuat pengaruh antara kesesuaian kompensasi dan kecurangan. Hasil ini sesuai dengan penelitian Aswad et al. (2018) yang menerangkan pemberian kompensasi yang sesuai serta menjalankan sistem dengan baik bisa mencegah perilaku curang. Peningkatan SPI dapat memicu perbaikan sistem kerja dan kontrol yang dapat mengurangi kesempatan terjadinya kecurangan. Ramadhany et al. (2017) menyatakan bahwa kompensasi adalah masalah yang mempunyai pengaruh pada perilaku seseorang. Sistem pengedalian internal yang baik yang diterapkan dalam organisasi akan memperkuat hubungan berbagai variabel termasuk sistem kompensasi dalam mengurangi kecurangan karena SPI adalah sistem yang diciptakan untuk mengontrol semua kegiatan yang ada dalam organisasi termasuk sistem kompensasi.

Hasil pengujian H5 menunjukkan bahwa SPI tidak dapat memoderasi peran auditor internal dan kecurangan. Artinya sistem pengendalian internal yang diterapkan di kabupaten TTS tidak berpengaruh terhadap hubungan peran auditor internal dan kecurangan. Auditor internal memiliki tanggung jawab melakukan pemeriksaan dan pengevaluasian terhadap efektivitas pengendalian internal dalam rangka membantu manajemen mencegah kecurangan. Kesempatan adanya tindak kecurangan akan berkurang dan juga ada jaminan keandalan serta keamanan aset jika pengendalian 
internal sudah sesuai (Lorensa et al,.2018 dan Pua et al., 2017). Namun, SPI hanya salah satu bagian yang diawasi oleh auditor internal. Ada atau tidak adanya sistem pengendalian internal, auditor internal sebagai pihak yang ditunjuk untuk mengawasi pemerintah daerah tetap akan melakukan perannya.

Hasil pengujian H6 menunjukan bahwa SPI tidak memoderasi budaya etis dan kecurangan. Artinya SPI yang diterapkan di kabupaten TTS tidak mempunyai pengaruh terhadap antara hubungan budaya etis dan kecurangan. Budaya organisasi berperan sebagai panutan dan cara yang menjadi panduan bagi semua orang dalam bersikap dan berperilaku dalam organisasi. Artinya peningkatan keefektifan organisasi melalui penerapan budaya dalam organisasi pada SPI dapat mengurangi kecurangan (Lorensa et al., 2018). Namun, Budaya etis organisasi merupakan kebiasaan yang terpisah dari sistem pemerintahan yang ada dikarenakan budaya adalah hasil dari kebiasaan yang dilakukan dalam organisasi. Sistem dirumuskan tapi budaya tercipta dari kebiasaan, artinya ada atau tidak adanya sistem pengendalian internal, budaya etis organisasi selalu menjadi bagian dari suatu organisasi karena ada suatu kebiasaan yang dilakukan dalam organisasi.

\section{PENUTUP}

Kesimpulan dari hasil penelitian adalah: 1). Kesesuaian kompensasi memiliki pengaruh negatif terhadap kecurangan; 2). Peran auditor internal tidak memiliki pengaruh terhadap kecurangan; 3). Budaya etis memiliki pengaruh negatif terhadap kecurangan; 4). SPI memperkuat pengaruh kesesuaian kompensasi terhadap kecurangan; 5). SPI tidak memoderasi peran auditor internal terhadap kecurangan; dan 6). SPI tidak memoderasi budaya etis terhadap kecurangan.

Keterbatasan penelitian adalah masih kurangnya transparansi dari responden dalam menjawab pernyataan dalam kuesioner, hal ini dilihat sebagian besar responden yang memberi jawaban netral dalam kuesioner. Selain itu, masih ada responden yang memberikan respon yang lebih menggambarkan harapan daripada keadaan riil. Saran peneliti bagi aparatur sipil negara di kabupaten Timor Tengah Selatan agar dapat memberikan jawaban terhadap pernyataanpernyataan kuesioner sesuai dengan keadaan yang sebenarnya karena setiap penelitian dapat menjadi bahan evaluasi untuk instansi di lingkungan pemda. Hal ini perlu diperhatikan dengan meningkatkan transparansi dalam memberikan informasi kepada setiap peneliti.

\section{DAFTAR PUSTAKA}

Abdullahi, R dan N. Mansor. 2018. Fraud prevention initiatives in the Nigerian public sector Understanding the relationship of fraud incidences and the elements of fraud triangle theory. Journal of Financial Crime. Vol. 25 No. 2, 2018. pp. 527-544. DOI 10.1108/JFC-02-20150008

Alou, SD, V Ilat dan H Gamaliel. 2017. Pengaruh Kesesuaian Kompensasi, Moralitas Manajemen, Dan Keefektifan Pengendalian Internal Terhadap Kecenderungan Kecurangan Akuntansi Pada Perusahaan Konstruksi Di Manado. Jurnal Riset Akuntansi Going Concern. Vol. 12(1), 2017, Hlm.139-148

Antarwiyati, P dan RE. Purnomo. 2017. Motivasi Melakukan Fraud dan Faktor-Faktor Yang Mempengaruhinya. Jurnal Akuntansi \& Auditing Indonesia, Vol. 21 No. 2, Desember 2017. Hlm. 157-166

Asosiasi Auditor Intern Pemerintah Indonesia. 2014. Standar audit intern Pemerintah indonesia.

Aswad, H, A Hasan dan N Indrawati. 2018. FaktorFaktor Yang Mempengaruhi Kecenderungan Kecurangan Akuntansi Dengan Keefektifan Pengendalian Internal Sebagai Variabel ModerasI (Studi pada Perusahaan Perkebunan Kelapa Sawit Swasta di Provinsi Riau). Jurnal Akuntansi. Vol. 6, No. 2, April 2018 Hlm. $221-234$

Badan Pemeriksa Keuangan Republik Indonesia. 2015-2018. Ikhtisar Hasil Pemeriksaan Semester II Tahun 2015-2018

Chandrayatna, I Dewa GP dan MM Sari. 2019. Pengaruh Pengendalian Internal, Moralitas Individu Dan Budaya Etis Organisasi Pada Kecenderungan Kecurangan Akuntansi. EJurnal Akuntansi Universitas Udayana Vol.27.2.Mei (2019). Hlm. 1063-1093. DOI:

https://doi.org/10.24843/EJA.2019.v27.i02 .p09

Darmawiguna, IMY dan NP. Mimba. 2017. Pengaruh Penerapan Aparat Pengawas Intern Pemerintah Terhadap Penerapan Good Governance dan Implikasinya pada Kinerja Pemerintah. E-Jurnal Akuntansi Universitas Udayana. Vol.18.3. Maret 2017, Hlm. 2172-2201

Dewi, CKR, Surya R.,dan MA Hasan. 2017. Pengaruh Pengendalian Internal, Kesesuaian Kompensasi, Ketaatan Aturan Akuntansi, Dan Perilaku Tidak Etis Terhadap Kecenderungan Kecurangan 
Akuntansi (Studi Empiris Pada SKPD Kabupaten Bengkalis). JOM Fekon. Vol. 4 No. 1. Februari 2017. Hlm. 1443-1457

Didi, dan IC. Kusuma. 2018. Faktor-Faktor Yang Berpengaruh Terhadap Kecenderungan Kecurangan (Fraud): Persepsi Pegawai Pemerintah Daerah Kota Bogor. Jurnal Akuntansi dan Keuangan Indonesia, Juni 2018, Vol. 15, No. 1.Hlm. 1 - 20

Fakta TTS. http://fakta-tts.com/ragam/2018/pemdatts-bocor-rp-25-miliar-sekda-ungkap-caramainnya/. Diakses pada tanggal 25 Maret 2019

Fitri, Cut IW. 2018. Pengaruh Budaya Organisasi Dan Peran Auditor Internal Terhadap Pencegahan Fraud. Jurnal Akuntansi Universitas Negeri Padang, Vol 6, No 3 (2018).

Fitri, F dan Nadirsyah. 2019. Pengaruh Tekanan (Pressure), Kesempatan (Opportunity), Rasionalisasi (Rationalization), Dan Kapabilitas (Capability) Terhadap Kecurangan Pengadaan Barang/Jasa Di Pemerintahan Aceh Dengan Pemoderasi Budaya Etis Organisasi. Jurnal Ilmiah Mahasiswa Ekonomi Akuntansi (JIMEKA). Vol. 4, No. 3, (2019) Hlm. 412-427

Karyono. 2013. Forensic Fraud. Yogyakarta (ID): Penerbit ANDI

Kurniasari N.T. 2017. Strategi Pencegahan Kecurangan (Fraud) Dalam Pengelolaan Keuangan Badan Litbang Dan Inovasi Kementerian Lingkungan Hidup Dan Kehutanan. Tesis. Sekolah Pascasarjana Institut Pertanian Bogor.

Lorensa, CN, S Fallah dan MA Sanggenafa. 2018. Pengaruh Budaya Organisasi Dan Peran Auditor Internal Terhadap Pencegahan Kecurangan Dengan Komponen Struktur Pengendalian Internal Sebagai Variabel Intervening (Studi Empiris Pada Inspektorat Provinsi, Kabupaten dan Kota Jayapura). Jurnal Akuntansi \& Keuangan Daerah. Vol.13, No. 2, November 2018. Hlm. 13-25

Muhammad, R dan Ridwan. 2017. Pengaruh Kesesuaian Kompensasi, Penerapan Sistem Informasi Akuntansi, Dan Efektivitas Pengendalian Internal Terhadap Kecurangan Akuntansi Studi Pada Bank Perkreditan Rakyat (BPR) Di Kota Banda Aceh. Jurnal Ilmiah Mahasiswa Ekonomi Akuntansi (JIMEKA) Vol. 2, No. 4, (2017) Hlm.136-145

Peraturan Pemerintah Republik Indonesia Nomor 60 Tahun 2008 Tentang Sistem Pengendalian Intern Pemerintah
Permana B.A, Perdana H.D, Kurniasih L. 2017. Determinant of Fraud in Government Agency: Empirical Study At The Finance And Development Supervisory Agency (BPKP) Of Jakarta Representative Office. Asia Pasific Fraud Journal. 2 (1):93108.doi.10.21532/apfj.001.17.02.01.08

Priantara D. 2013. Fraud Auditing \& Investigation. Jakarta (ID): Mitra Wacana Media

Pua, BY, JJ Sondakh, dan S Pangerapan. 2017. Evaluasi Fungsi Auditor Internal Dalam Pendeteksian dan Pencegahan Fraud Pada PDAM Airmadidi. Jurnal Riset Akuntansi Going Concern.Vol.12 (2), 2017, Hlm. 452-469

Putra, I Putu AP dan MY Latrini. 2018. Pengaruh Pengendalian Internal, Budaya Organisasi, Dan Moralitas Pada Kecenderungan Kecurangan (Fraud) Di Lpd Se-Kabupaten Gianyar. E-Jurnal Akuntansi Universitas Udayana Vol.25.3.Desember (2018). Hlm. 2155- 2184.2 DOI: https://doi.org/10.24843/EJA.2018.v25.103 .p20

Ramadhany, I, N Indrawati, dan Al Azhar L. 2017. Pengaruh Sistem Pengendalian Intern, Asimetri Informasi, Kesesuaian Kompensasi Dan Implementasi Good Corporate Governance Terhadap Kecenderungan Kecurangan Akuntansi (Studi Empiris pada Rumah Sakit Swasta yang ada di Pekanbaru). JOM Fekon. Vol. 4 No. 1. Februari 2017. Hlm. 1253-1267

Robbins, SP dan TA. Judge. 2016. Perilaku Organisasi Organizational Behavior Edisi 16. Jakarta (ID): Salemba Empat.

Rosliana. 2018. Pengaruh Pengendalian Internal Dan Budaya Etis Organisasi Terhadap Kecenderungan Kecurangan Akuntansi Pada Perbankan Di Pekanbaru. Jurnal Akuntansi dan Keuangan. Vol. 7, N0. 1, Januari - Juni 2018. Hlm. 1-8

Sekaran, U., \& Bougie, R. (2016). Research Methods for Business: a Skill building approach (Seventh ed). United Kingdom: Jhon Wiley \& Sons Ltd.

Soehari, TD, I. Budiningsih, UK. Tjiptoningsih, dan RK. Hanum. 2018. The Determinant Factors of Strategic Fraud. European Research Studies Journal Volume XXI, Special Issue 3, 2018. Hlm. 455-469

Virmayani, PC, NL Sulindawati, dan AT Atmadja. 2017. Pengaruh Kesesuaian Kompensasi, Asimetri Informasi, Budaya Etis Organisasi dan Komitmen Organisasi Terhadap Kecenderungan Kecurangan (Fraud) Akuntansi Pada KoperasiSimpan Pinjam Se-Kecamatan Buleleng. e-Journal 
S1 Ak Universitas Pendidikan Ganesha. Vol.7, No.1 tahun 2017

Wahyuni, dan GS Budiwitjaksono. 2017. Fraud Triangle Sebagai Pendeteksi Kecurangan Laporan Keuangan. Jurnal Akuntansi. Vol.XXI, No.01, Januari 2017, Hlm.47-61

Widyaswari, I Dewa AN, GA Yuniarta, dan E Sujana. 2017. Pengaruh Keefektifan Pengendalian Internal, Kesesuaian Kompensasi, Dan Budaya Organisasi Terhadap Kecenderungan Kecurangan
(Fraud) Pada Lembaga Perkreditan Desa (LPD) Se-Kecamatan Susut. e-Journal S1 Ak Universitas Pendidikan Ganesha. Vol.8, No.2 tahun 2017

Zelmiyanti R, Lili A. 2015. Pengaruh Budaya Organisasi Dan Peran Auditor Internal Terhadap Pencegahan Kecurangan Dengan Pelaksanaan Sistem Pengendalian Internal Sebagai Variabel Intervening. Jurnal Akuntansi Keuangan Dan Bisnis Vol. 8, November 2015, 67-76 